\title{
Can Supplementation of Vitamin D Improve Aerobic Capacity in Well Trained Youth Soccer Players?
}

\author{
by \\ Maria Jastrzębska ${ }^{1}$, Mariusz Kaczmarczyk ${ }^{3}$, Małgorzata Michalczyk ${ }^{9}$, \\ Łukasz Radzimiński, Piotr Stępieńn ${ }^{2}$ Joanna Jastrzębska ${ }^{6}$, Dorota Wakuluk10, \\ Arturo Díaz Suárez ${ }^{5}$, Guillermo Felipe López Sánchez ${ }^{5}$, Paweł Cięszczyk ${ }^{7,10}$, \\ Piotr Godlewski10, Paweł Król ${ }^{8}$, Zbigniew Jastrzębski ${ }^{4}$
}

There is no clear evidence that vitamin D effectively improves physical capacity in high-level athletes. The aim of this study was to confirm that vitamin D supplementation of soccer players during eight-week high-intensity training would have a significant effect on their aerobic capacity. The subjects were divided into two groups: the experimental one that was supplemented with vitamin $D(S G, n=20)$, and the placebo group $(P G, n=16)$, not supplemented with vitamin D. All the players were subjected to the same soccer training described as High-Intensity Interval Training (HIIT). The data of the vitamin D level, PWC170, lactate threshold (LT) were collected just before and after the intervention. A significant increase in vitamin D concentration (119\%) was observed in the supplemented group, while the non-supplemented group showed a decrease of $8.4 \%$. The studied subjects improved VO2max results by $20 \%$ in the SG, and by $13 \%$ in the PG. The improvement in velocity at the LT was similar in both groups. Results of this study show that vitamin $D$ can have a positive, though moderate, effect on aerobic performance in players subjected to high-intensity training in the form of small-sided games for 8 weeks.

Key words: soccer, training load, nutrition, youth athletes.

\section{Introduction}

The role of active vitamin $\mathrm{D}$ in calciumphosphorus balance and its influence on the metabolism of bones was known as long as 100 years ago (Wolf, 2004). Proliferative effect of this vitamin was identified only after the discovery of its nuclear receptor - VDR. It occurred that the receptor was present in numerous organs beyond the skeletal system, e.g. in the kidneys, the heart, the brain, the pancreas, the intestines as well as in muscles and skin (Bikle, 2009). It was also confirmed that vitamin D played an important role in immunological processes, showing antiinflammatory, anti-apoptosis, anti-fibrinolytic, and even antitumor activity (Lai and Fang, 2013).

1 - University Clinical Centre of Gdańsk, Poland.

2 - Higher Sport School in Lodz, Poland.

3 - Pomeranian Medical University Szczecin, Poland.

4- Faculty of Tourism and Recreation, Gdansk University of Physical Education and Sport, Poland.

5 - Faculty of Sport Sciences, University of Murcia, Spain.

6- Medical University of Gdańsk, Poland.

7 - Faculty of Physical Education, The Jerzy Kukuczka Academy of Physical Education in Katowice, Katowice, Poland.

8. University of Rzeszów, Poland.

9 - Department of Sports Nutrition, The Jerzy Kukuczka Academy of Physical Education in Katowice, Katowice, Poland.

10 - Faculty of Physical Education, Gdansk University of Physical Education and Sport, Poland. 
Moreover, its role in cell differentiation and inhibition of cell proliferation was proven (Bikle, 2009).

The effects of vitamin D on various life processes and functions of organs as well as the possibility of its application in disease prevention or treatment were the object of many scientific studies conducted mainly on older or ill people (Kestenbaum et al., 2011).

Relatively few studies have focused on young, healthy, and physically active subjects. Previous research considered the effect of vitamin D on the work of skeletal muscles (Girgis et al., 2014; Stockton et al., 2011; Ostrowski et al., 2012), bone metabolism (Solarz et al., 2014), and injury risk (Medina et al., 2014; Czuba et al., 2014; Lehnert et al., 2018). Tenforde et al. (2016) claimed that vitamin D was necessary for muscles to function optimally and to prevent bones from overuse fracture, a frequent risk for competitive athletes. Common injuries in youth athletes can be the result of high vitamin D deficiency related to physical activity, as well as limited exposure to solar radiation, especially in countries with low solar radiation in the winter (Farrokhyar et al., 2015).

There is no clear evidence that vitamin D effectively improves physical capacity in highlevel athletes. Studies on this issue were conducted among athletes of various sport disciplines. Stockton et al. (2011) reviewed the literature about this topic and found high effectiveness of vitamin D supplementation on muscle strength in judo contenders, rowers, hockey players, track and field athletes, and dancers. Girgis et al. (2014) studied the effect of eight-month vitamin D supplementation on physical capacity, muscle efficacy and changes in the insulin level in physically active subjects.

The results of correlation between the vitamin $\mathrm{D}$ level in blood plasma and aerobic capacity in athletes are ambiguous (Dahlquist et al., 2015). According to the authors, the results depend on the research methods, the type of sport, and training experience. There are few authors who studied this phenomenon in soccer players. Koundourakis et al. (2014) found a correlation between the vitamin $\mathrm{D}$ level and the efficiency of the neuro-muscular system in professional soccer players. They also confirmed the significant linear relationship between
$\mathrm{VO}_{2 \max }$ and the level of vitamin $\mathrm{D}$ in soccer players. This could have a positive effect on the level of stress connected to the intense physical effort during the competitive season. The significant relationship between the efficiency of the cardiovascular system, determined by the $\mathrm{VO}_{2 \max }$ index and vitamin $\mathrm{D}$ level in a group of 470 Europeans aged 12.5-17.5 (from Spain, Greece, Belgium, Germany, etc.) was presented by Valtuena et al. (2013). The authors did not find correlations in a group of 536 female subjects from the same countries, apart from muscle strength of upper limbs and the vitamin D level. However, different results were presented by Książek et al. (2016), who found no significant relationship between muscle strength and VO2max in professional soccer players from Poland tested during the winter, the season of the highest vitamin D deficiency. It must be stated, however, that the effect of vitamin D supplementation in the players during the season of its deficiency was not studied, and the test was performed only once. It was probably connected with the logistical difficulties in providing the specific nutrition for the large group during a long period (8-12 weeks), which is easier in individual sports. The need for vitamin $\mathrm{D}$ supplementation during and directly after the winter season in countries of northern Europe was suggested by Kopeć et al. (2013). They found a significantly lower level of vitamin $\mathrm{D}$ in the players during this time compared to the summer. Although it showed no significant effect on the bone metabolism, they suggested constant monitoring of calcium and parathyroid hormone (PTH) concentration in soccer players. A similar study, yet in professional players, was conducted in Spain by Galan et al. (2012). The authors suggested that even in this country with a high rate of solar exposure, during the winter (February) vitamin D levels can drop below $75 \mathrm{nmol} / \mathrm{L}$ (64\% of players) what may require supplementation.

In our opinion, the relationship between vitamin D concentration and aerobic capacity in active people is determined by numerous factors, e.g. the type of practiced sport, applied training loads or sport experience. Considering the fact of common deficiency of vitamin D in youth athletes, especially in northern Europe, as well as the possibility of excessive consumption of vitamin $\mathrm{D}$ by people submitted to high-intensity 
training, we evaluated the effects of vitamin D supplementation on aerobic capacity in youth soccer players during an eight-week highintensity training period.

\section{Methods}

\section{Experimental Approach to the Problem}

The experiment was performed during an eight-week training cycle of the preparatory season in the winter, from January to March, during the time when the solar exposure in Poland is low and as previously described by Jastrzębska et al. (2016). The subjects were divided into two groups: the experimental one that was supplemented with vitamin D (SG), and the placebo group (PG), not supplemented with vitamin D. All the players were subjected to the same soccer training described as High-Intensity Interval Training (HIIT) that involved endurance, speed and strength drills. Just before and after the experiment, blood samples for the vitamin D level estimation were taken from the players. The $\mathrm{PWC}_{170}$ test was performed to determine total work achieved at $170 \mathrm{HR} / \mathrm{min}$ and $\mathrm{VO}_{2 \max }$. Moreover, the players performed an Incremental Lactate Test to determine running velocity at the lactate threshold ( $\mathrm{V}_{\mathrm{LT}}$ ) and maximal intensity $\left(\mathrm{V}_{\max }\right)$. Small-sided games and interval runs at the lactate threshold were performed on the field with a synthetic surface. The intensity of the effort was determined by the heart rate (HR) that was equal or higher than the lactate threshold (HR/LT) value, but did not exceed $90 \%$ of the HRmax. Smallsided games were performed on a field of $32 \times 22$ m ( 3 vs 3 on Tuesday) and $44 \times 33$ m (6 vs 6 on Thursday) with $120 \mathrm{~m}^{2}$ of the surface per player. The subjects of both groups played 4 games, $4 \mathrm{~min}$ each with $3 \mathrm{~min}$ active rest periods that involved low intensity drills. On Fridays the players performed 4 sets, 5 min each, of interval running with $3 \mathrm{~min}$ active rest intervals (as in small-sided games). On the other days of each microcycle the players carried out speed and explosive strength drills and typical technical and tactical drills.

\section{Subjects}

The study was conducted on 36 soccer players (age: $17.5 \pm 0.6$ years, body mass $71.3 \pm 6.9$ $\mathrm{kg}$, BMI $\left.22.2 \pm 1.8 \mathrm{~kg} / \mathrm{m}^{2}\right)$, members of a sports school (Poland) that educated the highly talented youth. The subjects were divided into two groups: the placebo one, $n=16$ (that was subjected to HIIT only), and the experimental one, $\mathrm{n}=20$ (that was subjected to HIIT and vitamin $\mathrm{D}_{3}$ supplementation). The selection was done deliberately. The subjects showed no differences in terms of aerobic power determined by $\mathrm{PWC}_{170}$ and $\mathrm{VO}_{2 \max }$ (homogenous groups), and the position on the field (equal number of players of the same position in both groups). The participation rate in training sessions of the analyzed players reached $95 \%$. All the subjects involved in the experiment lived in the school dormitory and were nourished in the same way. The diet of players was standard, but included an increased amount of vegetables, fruit and dairy products. One month before and during the experiment, players did not take any vitamins or other sports supplements. All the participants had valid medical examinations. The protocol was fully approved by the Ethical Committee of the Medical Association in Gdańsk (Nr KB - 1/14). All the subjects and their parents or guardians gave their written consent to participate in the study.

\section{Procedures}

Vitamin $D_{3}$ supplementation and analysis

Each subject from the supplemented group was given vitamin $\mathrm{D}_{3}$ in a liquid form (Vigantol Merck) and was asked to take 10 droplets per day (about $5000 \mathrm{IU} /$ day) in the morning for 8 weeks during the study. The placebo group received identical-looking bottles containing sunflower oil. The dispensation procedure was double-blind.

Exposure to sun in the countries of northern Europe (Norway, Sweden, Finland) or central Europe (Poland, Czech Republic, Slovakia) is low. Therefore vitamin $\mathrm{D}$ acquisition in a natural way in these countries is minimal. Both supplementation and testing were carried out in late winter from January to the beginning of March. During the intervention, the subjects consumed specially prepared drinks before training under control of a physiotherapist who was unaware of to which group each subject belonged.

The measurements of $25(\mathrm{OH}) \mathrm{D}$ concentration were done before and 8 weeks after the intervention. Plasma 25(OH)D concentration (range, $50-125 \mathrm{nmol} / \mathrm{L}$ ) was evaluated by the standard method of BIOMÈRIEUX, MarcyI'Etoile, France (kit $n^{\circ}$ 30463) using a mini Vidas analyzer, of the same company. The intra-assay 
$\mathrm{CV}$ of the method was $2.4-6.4 \%$, with respect to the range.

Incremental Lactate Test

The individual maximum intensity run and the run at the lactate threshold of the player were determined as previously described (Radziminski et al., 2010) on a synthetic field at the beginning of the intervention. The test protocol included 3.5-5 $\mathrm{min}$ running stages separated by a 1-min rest interval, during which capillary blood samples were taken from the fingertip. The initial speed was set at $2.8 \mathrm{~m} \cdot \mathrm{s}^{-1}$ and increased by $0.4 \mathrm{~m} \cdot \mathrm{s}^{-1}$ after each stage until volitional exhaustion. The $D_{\max }$ method (Cheng et al., 1992) was used to determine the lactate threshold (VLT), running velocity, and HR/LT. Blood samples were evaluated using a Random Access Automatic Biochemical Analyzer for Clinical Chemistry and Turbidimetry A15 (BIOSYSTEMS S.A., Barcelona, Spain). Lactate concentration was measured using a Randox Manual/ Rx Monza LC 2389 kit. Manufacturer's declared intra-assay coefficients of variation $(\mathrm{CV})$ of the method were $3.62 \%$. The maximum heart rate $\left(\mathrm{HR}_{\max }\right)$ was determined during the stress test. If a higher HR value was observed during small-sided games, the higher value was used as the HRmax.

PWC 170 test

The $\mathrm{PWC}_{170}$ tests were performed under laboratory conditions. The aim of this test was to determine the index of total work performed at the $\mathrm{HR}$ of $170 \mathrm{bpm}$ using extrapolation, and to estimate $\mathrm{VO}_{2 \max }$ indirectly. The subjects refrained from any physical training or activity at least one day prior to the test. Just before the test, body mass was measured with an electronic scale Tanita TBF 300M (Tanita, Tokio, Japan). The $\mathrm{PWC}_{170}$ test was performed on a cycloergometer (Monark Ergomedic 830 E, Monark, Sweden). Before the test, each subject adjusted the saddle of the cycloergometer to his body height and had a portable heart rate monitor attached (Polar Electro OY, Finland). During the test, the load was administered individually so that the first 5-min effort raised the player's HR up to $120-130 \mathrm{bpm}$ and the second up to $150-160 \mathrm{bpm}$. Mean value of the HR was registered in the last minute of each 5min stage (Campbell et al., 2001).

\section{Statistical Analyses}

Data were analyzed using a within- subject modeling approach (http://www.sportsci.org) and analysis of covariance (ANCOVA) with pre-training values as covariates. Both, pre-training measures and training responses were compared using $t$ tests, an independent sample $t$ test for unequal variances for pre-training and a dependent sample $t$ test for the responses. In addition, the post- and pre-training difference (a change score) was calculated for each participant and the mean change scores were compared between the SG and PG with the $t$ test for unequal variances and ANCOVA. To estimate the magnitude of the supplementation effect, the mean change score in non-supplemented players was subtracted from the mean change score in supplemented individuals. The difference in the mean change score was then standardized with a presupplementation standard deviation calculated for all supplemented and non-supplemented players according to the method proposed by Hopkins (2015). The differences in mean change and standardized difference were reported with 95\% confidence limits. The magnitude of individual responses to training was classified as described by Hopkins (2015). SDIR, a measure of individual response, was calculated as the square root of the difference between squares of the standard deviations of the change scores in the supplemented and control groups. The remaining analyses were performed using STATISTICA (StatSoft, Inc. (2014), version 12, www.statsoft.com). A $\quad p$ value $<0.05$ was considered significant.

\section{Results}

Initial plasma concentration of $25(\mathrm{OH}) \mathrm{D}$ in both supplemented and control groups was below $50 \mathrm{nmol} / \mathrm{l}$, which was recognized as inadequate (deficiency) according to the Institute of Medicine recommendations (Close et al., 2013). In addition, initial 25(OH)D levels did not differ between supplemented and placebo groups (48.5 \pm 8.6 vs $47.5 \pm 16.2 \mathrm{mmol} / \mathrm{l}, p=0.817$, difference in the mean of 1.05 , Cohenized difference in the mean of 0.09). In the supplemented group, the plasma $25(\mathrm{OH}) \mathrm{D}$ level increased significantly after the intervention (initial $48.5 \pm 8.6 \mathrm{mmol} / \mathrm{l}$, after intervention $106.3 \pm 26.6 \mathrm{mmol} / \mathrm{l}$, mean change $57.8 \pm 21.7 \mathrm{mmol} / \mathrm{l}, p<0.0001)$, while in the placebo group only non-significant changes were 
observed (initial $47.5 \pm 16.2 \mathrm{mmol} / \mathrm{l}$, after intervention $43.5 \pm 16.7 \mathrm{mmol} / \mathrm{l}$, mean change of $4.0 \pm 12.7 \mathrm{mmol} / \mathrm{l}, p=0.228$ ).

With one exception (HR $\max$, supplemented group: $194.05 \pm 6.5 \mathrm{~b} \cdot \mathrm{min}^{-1}$, placebo group: $199.6 \pm$ $3.6 \mathrm{~b} \cdot \mathrm{min}^{-1}, p=0.003$ unequal variances t-test), initial values did not differ significantly between the supplemented and placebo groups.

Responses of aerobic fitness variables to HIIT are presented in Table 1. Each of the variables, except for the $H R$ and $H_{L T} / H_{\text {max, }}$ improved significantly following the training program.

However, when the mean change scores were stratified according to supplementation status, significant differences in the mean change scores between the SG and PG were observed for $\mathrm{PWC}_{170}$ and $\mathrm{VO}_{2 \max }$ (Table 2). Despite the lack of statistically significant differences for $V_{\max }, \mathrm{HR}_{\max }$, $\mathrm{HR}_{\mathrm{LT}}$, the effect size (difference in the mean change score between the SG and PG divided by pre-training $\mathrm{SD}$ ) was greater than 0.2 .

There was no evidence for greater variability in response to training in the supplemented group compared to the non-supplemented group (Table 2, SDIR). Although SDIR was greater than 2 for the $H_{\text {max }}$ representing an extremely large effect, i.e. large variation between the net mean effect of the vitamin D supplementation, the $95 \%$ confidence interval covered negative values, implying more variation in the PG as compared with the SG.

\begin{tabular}{|c|c|c|c|c|}
\hline \multicolumn{5}{|c|}{$\begin{array}{l}\text { Table } \\
\text { Pre- and post-intervention values of aerobic capacity-related variables }\end{array}$} \\
\hline Variable & Pre-Intervention & Post-Intervention & Change & $p^{\mathrm{a}}$ \\
\hline $\mathrm{V}_{\max }(\mathrm{m} / \mathrm{s})$ & $4.68 \pm 0.21$ & $4.76 \pm 0.13$ & $0.08 \pm 0.19$ & 0.017 \\
\hline $\mathrm{V}_{\mathrm{LT}}(\mathrm{m} / \mathrm{s})$ & $3.34 \pm 0.32$ & $3.64 \pm 0.27$ & $0.30 \pm 0.24$ & $<0.0001$ \\
\hline $\mathrm{V}_{\text {LT }} / \mathrm{V}_{\max }(\%)$ & $71.4 \pm 6.1$ & $76.5 \pm 5.4$ & $5.2 \pm 5.8$ & 0.000006 \\
\hline $\mathrm{HR}_{\max }$ (beats/min) & $197 \pm 6$ & $193 \pm 6$ & $-4.0 \pm 6.0$ & 0.0001 \\
\hline HRLt (beats/min) & $174 \pm 9$ & $173 \pm 6$ & $-1.2 \pm 8.6$ & 0.423 \\
\hline $\mathrm{HR}_{\mathrm{LT}} / \mathrm{HR}_{\max }(\%)$ & $89 \pm 5$ & $90 \pm 3$ & $1.2 \pm 4.5$ & 0.122 \\
\hline $\mathrm{PWC}_{170}(\mathrm{kGm} / \mathrm{kg} / \mathrm{min})$ & $14.8 \pm 2.3$ & $19.1 \pm 1.8$ & $4.3 \pm 2.3$ & $<0.0001$ \\
\hline $\mathrm{VO}_{2 \max }(\mathrm{ml} / \mathrm{kg} / \mathrm{min})$ & $42.6 \pm 4.1$ & $49.9 \pm 3.7$ & $7.3 \pm 3.9$ & $<0.0001$ \\
\hline $\begin{array}{r}\text { mean chan } \\
\text { a depen } \\
V_{L T} / V_{\max }-\text { runn } \\
H R_{\max } \\
P W C_{1}\end{array}$ & $\begin{array}{l}\text { ore - the differen } \\
\text { sample Student' } \\
V_{L T}-\text { running } \\
\text { elocity at the lac } \\
\text { ximal heart rate; } \\
\text { shysical work cap }\end{array}$ & $\begin{array}{l}\text { tween post-and } p \\
\text { est; } V_{\text {max }} \text { - maximo } \\
\text { ity at lactate thre } \\
\text { hreshold and max } \\
T-\text { heart rate at th } \\
\text {; VO } O_{2 \max } \text { - maxim }\end{array}$ & $\begin{array}{l}\text { tervention } \\
\text { ning veloc } \\
\text { running ve } \\
\text { tate thresho } \\
\text { ygen uptak }\end{array}$ & yatio; \\
\hline
\end{tabular}




\begin{tabular}{|c|c|c|c|c|c|}
\hline \multirow{3}{*}{ Variable } & \multicolumn{2}{|c|}{$\begin{array}{rr}\text { Table } 2 \\
\text { he effect of vitamin D supplementation on aerobic fitness-related variables. }\end{array}$} & \multicolumn{3}{|c|}{$\begin{array}{l}\text { Table } 2 \\
\text { ation on aerobic fitness-related variables. }\end{array}$} \\
\hline & \multicolumn{2}{|c|}{ Group (change score) } & \multirow{2}{*}{$p^{\mathrm{a}}$} & \multirow{2}{*}{$\begin{array}{c}\text { Difference in mean } \\
\text { change (standardized) }\end{array}$} & \multirow{2}{*}{ SDIR } \\
\hline & $S G(n=20)$ & PG $(n=16)$ & & & \\
\hline $\mathrm{V}_{\max }(\mathrm{m} / \mathrm{s})$ & $0.04 \pm 0.12$ & $0.13 \pm 0.24$ & $\begin{array}{l}0.213 / \\
0.197\end{array}$ & $\begin{array}{l}-0.08 \pm 0.11 \\
(-0.40 \pm 0.54)\end{array}$ & $-0.21(-0.28-0.08)$ \\
\hline $\mathrm{V}_{\mathrm{LT}}(\mathrm{m} / \mathrm{s})$ & $0.29 \pm 0.22$ & $0.31 \pm 0.26$ & $\begin{array}{r}0.852 / \\
0.914\end{array}$ & $\begin{array}{l}-0.02 \pm 0.14 \\
(-0.05 \pm 0.44)\end{array}$ & $-0.14(-0.27-0.17)$ \\
\hline $\mathrm{V}_{\mathrm{LT}} / \mathrm{V}_{\max }(\%)$ & $5.60 \pm 4.58$ & $4.60 \pm 7.14$ & $\begin{array}{c}0.631 / \\
0.457\end{array}$ & $\begin{array}{c}1.00 \pm 3.52 \\
(0.16 \pm 0.58)\end{array}$ & $-5.49(-7.92-1.59)$ \\
\hline $\begin{array}{l}\mathrm{HR}_{\max } \\
\text { (beats/min) }\end{array}$ & $-2.55 \pm 5.73$ & $-5.75 \pm 5.05$ & $\begin{array}{c}0.084 / \\
0.596\end{array}$ & $\begin{array}{c}3.20 \pm 3.04 \\
(0.53 \pm 0.51)\end{array}$ & $2.69(-4.00-5.52)$ \\
\hline HRLt (beats/min) & $-0.05 \pm 6.76$ & $-2.56 \pm 10.61$ & $\begin{array}{c}0.419 / \\
0.507\end{array}$ & $\begin{array}{c}2.51 \pm 5.22 \\
(0.29 \pm 0.60)\end{array}$ & $-8.17(-11.78-2.25)$ \\
\hline $\mathrm{HR}_{\mathrm{LT}} / \mathrm{HR}_{\max }(\%)$ & $1.14 \pm 3.19$ & $1.23 \pm 5.80$ & $\begin{array}{c}0.957 / \\
0.191\end{array}$ & $\begin{array}{l}-0.09 \pm 2.78 \\
(-0.02 \pm 0.57)\end{array}$ & $-4.85(-6.67-1.60)$ \\
\hline $\begin{array}{l}\mathrm{PWC}_{170} \\
(\mathrm{kGm} / \mathrm{kg} / \mathrm{min})\end{array}$ & $5.03 \pm 2.02$ & $3.34 \pm 2.28$ & $\begin{array}{l}0.027 / \\
0.0004\end{array}$ & $\begin{array}{c}1.69 \pm 1.23 \\
(0.73 \pm 0.53)\end{array}$ & $-1.06(-2.22-1.64)$ \\
\hline $\begin{array}{l}\mathrm{VO}_{2 \max } \\
(\mathrm{ml} / \mathrm{kg} / \mathrm{min})\end{array}$ & $8.65 \pm 3.57$ & $5.68 \pm 3.71$ & $\begin{array}{l}0.021 / \\
0.001\end{array}$ & $\begin{array}{c}2.97 \pm 2.07 \\
(0.73 \pm 0.51)\end{array}$ & $-1.02(-3.43-3.11)$ \\
\hline \multicolumn{5}{|c|}{$\begin{array}{l}\text { SG - group supplemented with vitamin D; for difference in mean change and standardized } \\
\text { (with pre-intervention SD) difference }\end{array}$} & \\
\hline $\begin{array}{r}95 \% \\
V_{L T} / V\end{array}$ & $\begin{array}{l}\text { in mean, } 9 \\
\text { nfidence lim } \\
\text { - running } v \\
\text { HR }_{\max }-\text { max } \\
\text { PWC } 170-p\end{array}$ & $\begin{array}{l}\text { confidence li } \\
\text { a measure } \\
\text { l brackets (H } \\
\text { running ve } \\
\text { ty at the lact } \\
\text { l heart rate; } \\
\text { cal work cap }\end{array}$ & $\begin{array}{l}\text { s are sh } \\
\text { udividu } \\
\text { ins, } 20 \\
\text { ty at th } \\
\text { thresho } \\
\mathrm{T}-\mathrm{hea} \\
\mathrm{y} ; \mathrm{VO}_{2}\end{array}$ & $\begin{array}{l}\text { l; } \\
S D_{I R}=\sqrt{S D_{S G}^{2}-S E} \\
\text { esponse, } \\
V_{\text {max }} \text { - maximal runn } \\
\text { ctate threshold; } \\
\text { nd maximal running } \\
\text { ate at the lactate thres } \\
\text { - maximal oxygen upt }\end{array}$ & $\begin{array}{l}\text { velocity; } \\
\text { ity ratio; }\end{array}$ \\
\hline
\end{tabular}

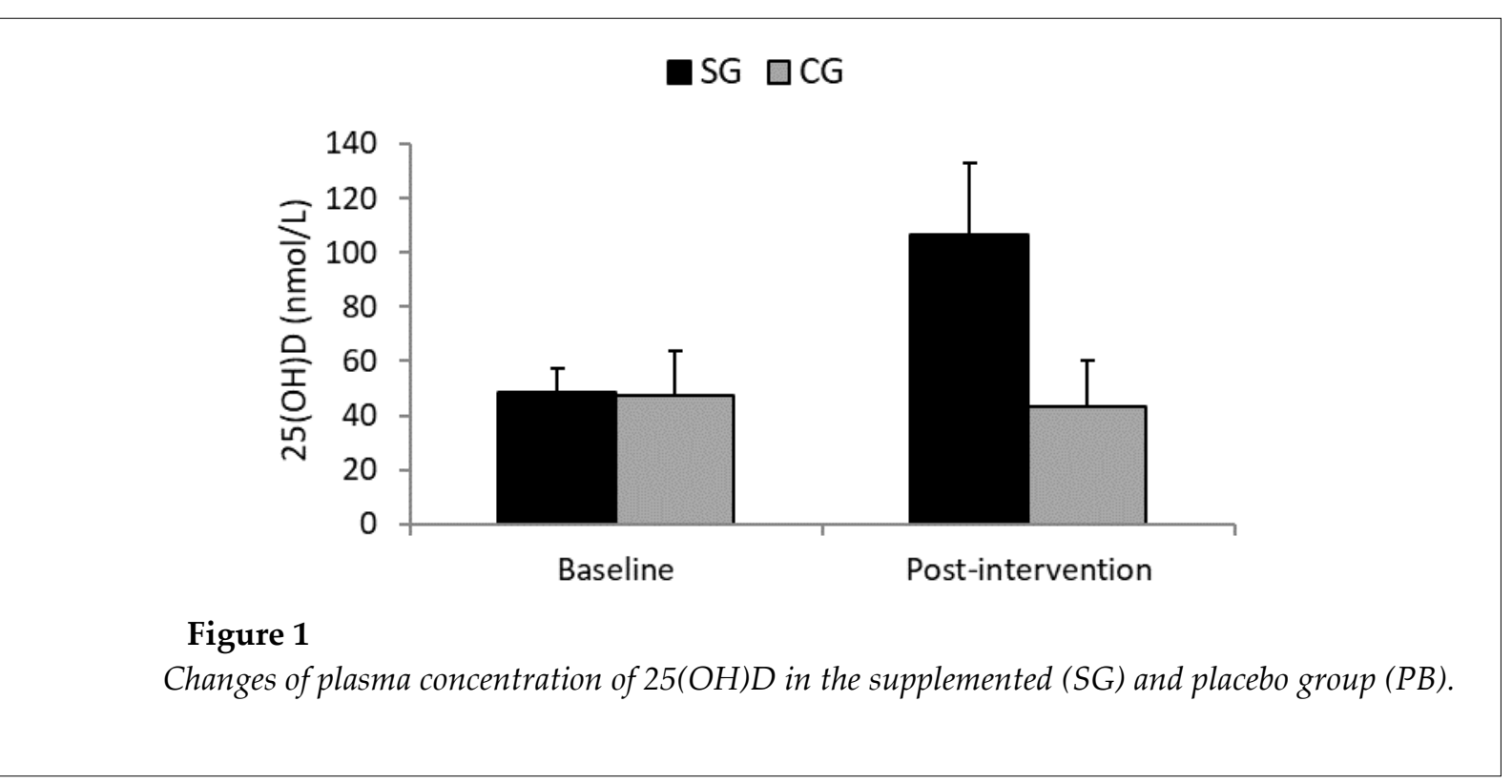




\section{Discussion}

The main asset of the study is the confirmation of the fact that vitamin D supplementation in soccer players during an eight-week high-intensity training program has a significant effect on the aerobic capacity. As a result, a considerable improvement of PWC170 and $\mathrm{VO}_{2 m a x}$ in the supplemented group was observed compared to non-supplemented subjects.

Considering the effects of training loads in both groups, apart from HR/AT and HR/AT $(\%)$, at the end of the intervention the improvement in aerobic capacity indices was observed (Table 1). Dahlquist et al. (2015) reviewed the literature regarding the effect of vitamin D supplementation on the performance of subjects in relation to their activity, age, gender and/or occupation. A high correlation was revealed between anaerobic capacity and high vitamin $\mathrm{D}$ concentration both naturally and as a result of supplementation. Yet, the results for anaerobic capacity vary according to different authors. Mowry et al. (2009) and Ardestani et al. (2011) found significant correlations between $\mathrm{VO}_{2 \max }$ and vitamin $\mathrm{D}$ concentration in untrained subjects, while Koundourakis et al. (2014) in professional soccer players and Forney et al. (2014) in university students of physical education. However, no correlations between vitamin $\mathrm{D}$ concentration and $\mathrm{VO}_{2}$ max were stated by Gregory et al. (2013) in resistance trained subjects practicing fitness, and Książek et al. (2016) in soccer players.

The only study on the effect of vitamin D supplementation on aerobic capacity expressed as VO2max was shown by Jastrzębski (2014) in 14 professional Polish rowers during eight-week high-intensity training. The study revealed that a dose of 6000 IU/day of vitamin D significantly increased the index by $12.7 \%$ in supplemented subjects, and by $10.2 \%$ in a control (nonsupplemented) group.

In this study, a similar dose of 5000 IU/day and high-intensity soccer training were applied. The effects were similar. The studied subjects improved $\mathrm{VO}_{2 \max }$ by $20 \%$ in the supplemented group, and by $13 \%$ in the nonsupplemented group. Also a significant increase in vitamin D concentration, $119 \%$ in the supplemented group, was observed, while the non-supplemented group showed a decrease of $8.4 \%$.

Dalhquist (2015) suggests that vitamin D concentration above $100 \mathrm{nmol} / \mathrm{L}$ can improve skeletal muscle function and recovery after performance, as well as strength, power and testosterone concentration. The author also says that application of 4000-5000 IU/day of vitamin D combined with $50-1000 \mathrm{mqg} /$ day of vitamin $\mathrm{K} 1$ and K2 can be assumed as safe and may contribute to improved performance. In our study, a dose of $5000 \mathrm{IU} /$ day was applied during 8 weeks without any other supplementation and an improvement in aerobic performance was observed. According to Ardestani et al. (2011) the specific effect of $\mathrm{VO}_{2 \max }$ improvement as a result of increased $25(\mathrm{OH}) \mathrm{D}$ concentration is unclear and can be related to increased affinity of oxygen to hemoglobin in the blood.

Based on our research, this effect can be observed in youth players subjected to high training loads, and the considerable improvement in another index of aerobic capacity PWC170 (Effect Size, $0.73 \pm 0.53$ ) supports this thesis.

Another key index of aerobic capacity, apart from $\mathrm{VO}_{2 \max }$ and PWC170, includes the Anaerobic Threshold (AnT). In our study it was determined by running velocity at the intensity corresponding to a non-linear increase of lactic acid concentration in the blood during exercise (Cheng et al., 1992). In both groups, the SG and PG, mean value of the VLT increase was $0.30 \pm$ $0.24 \mathrm{~m} \cdot \mathrm{s}^{-1}$ after the intervention and it was statistically significant. The effect is well-known, especially as a result of high-intensity training in soccer players (Iaia et al., 2009), and elite endurance athletes (Laursen and Jenkins, 2002). The fact that the difference in the increase of this index in supplemented and non-supplemented groups was not statistically significant can suggest that in youth soccer players, there can be other factors apart from supplementation influencing the results, for example technical skills and economy of movement, or anthropometric variables.

During small-sided games in soccer training, players reach $85-95 \%$ of the HRmax (Hill-Hass et al., 2009). Some researchers applied small-sided games in soccer training for 7-12 weeks and noticed maintenance of $\mathrm{VO}_{2 \max }$ in the subjects (Hill-Hass et al., 2009) or an increase of 
$5.2 \%$ (Jensen et al., 2007). Similarly, Impellizzeri et al. (2006) observed an increase in $\mathrm{VO}_{2 \max }(7.1 \%)$ as well as running velocity at the anaerobic threshold (VLT) of 9.7\% after 12-week small-sided game training in youth soccer players. In our study, the players improved their $\mathrm{VO}_{2 \max }$ by $17.1 \%$ $\left(42.6 \pm 4.1\right.$ vs $\left.49.9 \pm 3.7 \mathrm{ml} \cdot \mathrm{kg} \cdot \mathrm{min}^{-1}\right)$, and VLT by $9.0 \%\left(3.34 \pm 0.32\right.$ vs $\left.3.64 \pm 0.27 \mathrm{~m} \cdot \mathrm{s}^{-1}\right)$. The improvement of these indices in both groups after the termination of the experiment was the result of both high effectiveness of applied training and the fact that the experiment started after one month post-season recovery from December to January (Table 1). However, vitamin D supplementation could support energy production in players of the supplemented group and as a result improve the efficiency of the training process.

Such indices as HRmax and HRLT may indicate the direction of changes in aerobic capacity in players as a result of applied training loads or other factors.

After the intervention, both groups, the SG and PG, showed a decrease in mean values of $\mathrm{HR}_{\max }\left(197 \pm 6\right.$ vs $\left.193 \pm 6 \mathrm{~b} \cdot \mathrm{min}^{-1}\right)$, and HRLT (174 \pm 9 vs $173 \pm 6 \mathrm{~b} \cdot \mathrm{min}^{-1}$ ) (non-significant), but also an increase of $\operatorname{Vmax}\left(4.68 \pm 0.21\right.$ vs $\left.4.76 \pm 0.13 \mathrm{~m} \cdot \mathrm{s}^{-1}\right)$. The comparison of these indices between the groups (SG and PG) showed no significant differences. The results support the assumed thesis that the effect of applied training loads was high and improved aerobic performance to a greater extent than vitamin D supplementation.

It should be noticed that although the effect of vitamin D supplementation is in this case moderate and weaker than the intensity and volume of training loads, it can have a considerable effect during the periods of insufficient solar exposure during winter, which occurred in this experiment (Larson-Meyer and Willis, 2010).

According to our study, it may be assumed that vitamin D can have a positive, though moderate, effect on aerobic performance in players who apply high-intensity training in the form of small-sided games during limited exposure to sunlight. The study can be highly applicable for coaches who plan training loads for youth and adult soccer players. Apart from considering high intensity training in the form of small-sided games, they should also control vitamin D concentration in players. The subjects with low vitamin $\mathrm{D}$ levels should be supplemented with 4000-5000 IU/day during at least 4 weeks. These recommendations especially concern players who practice in winter in the countries with low solar radiation. Limited literature of the subject should induce both scientists and coaches to further research and explain the effect of vitamin D deficiency and its supplementation among athletes and their aerobic performance.

\section{Acknowledgements}

The study was designed by MJ, MK, and ZJ. PS, JJ, DW, and ŁR conducted the research. Data was interpreted and analyzed by MK, ADS, GFLS. All authors participated in writing the manuscript.

\section{References}

Ardestani A, Parker B, Mathur S, Clarkson P, Pescatello LS, Hoffman HJ, Polk DM, Thompson PD. Relation of vitamin D level to maximal oxygen uptake in adults. Am J Cardiol, 2011; 107(8): 1246-1249. http://doi.org/10.1016/j.amjcard.2010.12.022

Bikle D. Nonclassic actions of vitamin D. J Clin Endocrinol Metab, 2009; 94(1): 26-34. http://doi.org/10.1210/jc.2008-1454

Campbell PT, Katzmarzyk PT, Malina RM, Rao DC, Perusse L, Bouchard C. Am J Hum Biol, 2001; 13(2): 190196

Cheng B, Kuipers H, Snyder AC, Keizer HA, Jeukendrup A, Hesselink M. A new approach for the determination of ventilatory and lactate thresholds. Int J Sports Med, 1992; 13(7): 518-22. http://doi.org/10.1055/s-2007-1021309

Close GL, Russel J, Cobley JN, Owens DJ, Wilson G, Gregson W, Fraser WD, Morton JP. Assessment of 
vitamin D concentration in non-supplemented professional athletes and healthy adults during the winter months in the UK: implications for skeletal muscle function. J Sports Sci, 2013; 31(4): 344-353. http://doi.org/10.1080/02640414.2012.733822

Czuba M, Maszczyk A, Gerasimuk D, Roczniok R, Fidos-Czuba O, Zając A, Gołaś A, Mostowik A, Langfort J. The effects of hypobaric hypoxia on erythropoiesis, maximal oxygen uptake and energy cost of exercise under normoxia in elite biathletes. J Sports Sci Medic, 2014; 13(4): 912-920

Dahlquist DT, Dieter BP, Koehle MS. Plausible ergogenic effects of vitamin D on athletic performance and recovery. J Int Soc Sports Nutr, 2015; 12(1): 33. http://doi.org/10.1186/s12970-015-0093-8

Farrokhyar F, Tabasinejad R, Dao D, Peterson D, Ayeni OR, Hadioonzadeh R, Bhandari M. Prevalence of vitamin D inadequacy in athletes: a systematic-review and meta-analysis. Sports Med (Auckland, N.Z.), 2015; 45(3): 365-78. http://doi.org/10.1007/s40279-014-0267-6

Forney L, Earnest CC, Henagan T, Johnson L, Castleberry T, Stewart L. Vitamin D Status, Body Composition, and Fitness Measures in College-Aged Students. J Strength Cond Res, 2014; 28: 814-24.

Galan F, Ribas J, Sánchez-Martinez PM, Calero T, Sánchez AB, Muñoz A. Serum 25-hydroxyvitamin D in early autumn to ensure vitamin D sufficiency in mid-winter in professional football players. Clin Nutr, 2012; 31(1): 132-6. http://doi.org/10.1016/j.clnu.2011.07.008

Girgis CM, Clifton-Bligh RJ, Turner N, Lau SL, Gunton JE. Effects of vitamin D in skeletal muscle: falls, strength, athletic performance and insulin sensitivity. Clin Endocrinol (Oxf), 2014; 80(2): 169-181. http://doi.org/10.1111/cen.12368

Gregory SM, Parker BA, Capizzi JA, Grimaldi AS, Clarkson PM, Moeckel-Cole S, Keadle J, Chipkin S, Pescatello LS, Simpson K, White MC, Thompson PD. Changes in vitamin D are not associated with changes in cardiorespiratory fitness. Clin Med Res, 2013; 2: 68

Hill-Haas SV, Coutts AJ, Rowsell GJ, Dawson BT. Generic versus small-sided game training in soccer. Int J Sports Med, 2009; 30(9): 636-42. http://doi.org/10.1055/s-0029-1220730

Hopkins WG. Individual responses made easy. J Appl Physiol (Bethesda, Md.: 1985), 2015; 118(12): 1444-6. http://doi.org/10.1152/japplphysiol.00098.2015

Iaia FM, Rampinini E, Bangsbo J. High-Intensity Training in Football. Int J Sports Physiol Perform, 2009; 4: 291306

Impellizzeri FM, Marcora SM, Castagna C, Reilly T, Sassi A, Iaia FM, Rampinini E. Physiological and performance effects of generic versus specific aerobic training in soccer players. Int J Sports Med, 2006; 27(6): 483-92. http://doi.org/10.1055/s-2005-865839

Jastrzębska M, Kaczmarczyk M, Jastrzębski Z. The effect of vitamin d supplementation on training adaptation in well trained soccer players. J Strength Cond Res, 2016: 30(9): 2648-55. http://doi.org/10.1519/JSC.0000000000001337

Jastrzębski Z. Effect of vitamin D supplementation on the level of physical fitness and blood parameters of rowers during the 8-week high intensity training. Facicula Educ Fiz Si Sport, 2014; 2: 57-67

Jensen J, Randers M, Krustrup P, Bangsbo J. Effect of additional in-season aerobic high-intensity drills on physical fitness of elite football players. J Sports Sci Med, 2007; 6(10): 79

Kestenbaum B, Katz R, de Boer I, Hoofnagle A, Sarnak MJ, Shlipak MG, Jenny NS, Siscovick DS. Vitamin D, parathyroid hormone, and cardiovascular events among older adults. J Am Coll Cardiol, 2011; 58(14): 1433-41. http://doi.org/10.1016/j.jacc.2011.03.069

Kopeć A, Solarz K, Majda F, Słowińska-Lisowska M, Mędraś M. An evaluation of the levels of vitamin d and bone turnover markers after the summer and winter periods in polish professional soccer players. J Hum Kinet, 2013; 38: 135-40. http://doi.org/10.2478/hukin-2013-0053

Koundourakis NE, Androulakis NE, Malliaraki N, Margioris AN. Vitamin D and exercise performance in professional soccer players. PloS One, 2014; 9(7): e101659. http://doi.org/10.1371/journal.pone.0101659

Książek A, Zagrodna A, Dziubek W, Pietraszewski B, Ochmann B, Słowińska - Lisowska M. 25(OH)D3 
Levels Relative to Muscle Strength and Maximum Oxygen Uptake in Athletes. J Hum Kinet, 2016; 50(1): 71-77. http://doi.org/10.1515/hukin-2015-0144

Lai YH, Fang TC. The pleiotropic effect of vitamin D. ISRN Nephrology, 2013; 898125. http://doi.org/10.5402/2013/898125

Larson-Meyer DE, Willis KS. Vitamin D and athletes. Curr Sports Med Rep, 2010; 9(4): 220-226. http://doi.org/10.1249/JSR.0b013e3181e7dd45

Laursen PB, Jenkins DG. The Scientific Basis for High-Intensity Interval Training Optimising Training Programmes and Maximising Performance in Highly Trained Endurance Athletes. Sports Med, 2002; 32(1): 53-73 0112-1642/02/0001-0053/\$22.00/0

Lehnert M, De Ste Croix M, Xaverova Z, Botek M, Varekova R, Zaatar AMZ, Lastovicka O, Stastny P. Changes in injury risk mechanisms after soccer-specific fatigue in male youth soccer players. J Hum Kinet, 2018, 62: [InPress] doi: 10.1515/hukin-2017-0157

Medina D, Lizarraga A, Drobnick F. Injury prevention and nutrition in football. Sports Sci Exchange, 2014; 27(132): $1-5$

Mheid IAl, Ramadan R, Kavtaradze N, Morris A, Ali S, Aznaouridis K, Quyyumi A, Alexander RW, Brigham KL, Quyyumi A. Abstract 1723: Vitamin D Levels Are Associated With Exercise Capacity and Measures of Endothelial Function in Healthy Humans. Circulation, 2009; 120(18)

Mowry DA, Costello MM, Heelan KA. Association among cardiorespiratory fitness, body fat, and bone marker measurements in healthy young females. J Am Osteopath Assoc, 2009; 109(10): 534-9

Ostrowski A, Strzała M, Stanula A, Juszkiewicz M, Pilch W, Maszczyk A. The Role of Training in the Development of Adaptive Mechanisms in Freedivers. J Hum Kinet, 2012; 32: 197-210

Radziminski Ł, Rompa P, Dargiewicz R, Ignatiuk W, Jastrzebski Z. An application of incremental running test results to train professional soccer players. Baltic Journal of Health and Physical Activity, 2010; 2: 67-74

Solarz K, Kopeć A, Pietraszewska J, Majda F, Słowińska-Lisowska M, Mędraś M. An evaluation of the levels of 25-hydroxyvitamin D3 and bone turnover markers in professional football players and in physically inactive men. Physiol Res, 2014; 63(2): 237-43

Stockton KA, Mengersen K, Paratz JD, Kandiah D, Bennell KL. Effect of vitamin D supplementation on muscle strength: a systematic review and meta-analysis. Osteoporos Int, 2011; 22(3): 859-71. http://doi.org/10.1007/s00198-010-1407-y

Tenforde AS, Kraus E, Fredericson M. Bone Stress Injuries in Runners. Phys Med Rehabil, 2016; 27(1): 139-49. http://doi.org/10.1016/j.pmr.2015.08.008.

Valtueña J, Gracia-Marco L, Huybrechts I, Breidenassel C, Ferrari M, Gottrand F, Dallongeville J, Sioen I, Gutierrez A, Kersting M, Kafatos A, Manios Y, Widhalm K, Moreno LA, Gonzalez-Gross M, Helena Study Group. Cardiorespiratory fitness in males, and upper limbs muscular strength in females, are positively related with 25-hydroxyvitamin D plasma concentrations in European adolescents: the HELENA study. QJM, 2013; 106(9): 809-21. http://doi.org/10.1093/qjmed/hct089.

Wolf G. The discovery of vitamin D: the contribution of Adolf Windaus. J Nutr, 2004; 134(6): 1299-302

\section{Corresponding author:}

\section{Maria Jastrzębska}

University Clinical Centre of Gdańsk, Poland

80-952 Gdańsk,

ul. Dębinki 7

Phone: +48605444773

E-mail: mariajastrzebska@hotmail.com 